\title{
Aung Medical Qi Gong Retreat: Reinforcement of Practice
}

\author{
Steven KH Aung* \\ Faculty of Medicine and Dentistry, University of Alberta, Canada
}

Submission: March 09, 2018; Published: October 16, 2018

*Corresponding author: : Steven KH Aung, Faculty of Medicine and Dentistry, Pharmaceutical Sciences and School of Public Health, University of Alberta, Edmonton, Alberta, Canada, Email: draung@aung.com

\section{Perspective}

The self-cultivation of vital energy, which is what Qi Gong is all about, fits into the holistic, biopsychosocial model of primary care that has been emerging, slowly but surely, in conjunction with what has so aptly been termed the 'greening' of medicine [1]. Qi Gong is not a panacea, but an approach that complements biomedicine. It is, above all, a personal empowerment strategy that helps one function more effectively in daily life as a total human being [2]. The medical Qi Gong I teach embodies appreciation of the natural environment as well as loving kindness and compassion. Without loving kindness and compassion no healing therapy can be truly worthwhile [3].

Loving-kindness is a general Buddhist moral precept rather than a specific Buddhist medical concept, but it does have a direct and powerful therapeutic application. I was reminded of this in the fall of 1990 when I met with His Holiness the Dalai Lama at his office in Dharamsala. One of the questions I asked him was, "What is the difference between Buddhist medicine and Western medicine?" [4] The Dalai Lama's response was both simple and complex. He mentioned that Buddhist physicians always provide a blessing together with their healing therapies, whereas this is quite rare among Western practitioners. Thus, Buddhist physicians will also quietly or silently give the patient a mettã 'pill' as a normal and essential-component to the therapy [5].

This pill takes the form of ablessing, a silent or audible utterance of the phrase, mettã, which denotes 'loving kindness' and implies 'may you and all sentient beings sharing this universe with us be blessed with peace, harmony and good health.' Simply thinking or saying the phrase reminds the primary care practitioner that the therapy of choice must be safe, reliable and effective and that it must be competently applied in full consideration of the special needs and wants of every patient [6].

The complexity of the Dalai Lama's seemingly simple answer arises from the fact that mettã, when applied as an essential, vital ingredient in any therapy, entails considerable physical, mental and spiritual discipline on the part of practitioners. Mettã must be given with saydana (selflessness), karuna (compassion) and mudita (sympathetic joy). In engaging these four pillars of loving kindness it is extremely important to remember that physicians must first heal themselves, that the most difficult patients are the best teachers and that an attitude of genuine, heartfelt loving kindness is not easy to attain or sustain [7].

It is difficult for those who are unhealthy in body, mind, and spirit to be effective and/or compassionate with their patients. Therefore, practitioners must always seek to maintain and enhance their natural vital energy. Buddhist physicians learn this by way of various breathing, concentration/meditation, and still or moving posture techniques, which are collectively known as anapanasati [8]. Getting and keeping a sense of true loving kindness is a discipline that demands our constant attentiveness. It is a discipline that may, according to Buddhist philosophy, take several individual lifetimes to learn properly. Our fragile sense of loving kindness may often be threatened by disease, pain, old age, bereavement, stress, materialism, vice, crime, hatred, racism, war, and corruption [9].

Physicians and other primary care professionals receive substantial exposure to these negative factors, since their effects are virtually carried into the medical clinic every working day by patients. It is becoming much more common to hear biomedical personnel using the term tender loving care to describe the needs and wants of their patients. I view this as an indication that loving kindness is once again, after a few centuries of scientific reductionism, becoming part of the Western tradition of humanistic medicine. After all, the ancient Hippocratic oath, which is hanging framed on the wall above me as I write these humble words, alludes to loving-kindness. It states, for example, that the competent and caring physician will 'give no deadly medicine to anyone' and will 'abstain from every voluntary act of mischief and corruption' [10].

Mettã, even though the word itself is short and simple, has a deep and complex meaning. It is not easy to practice mettã $(+$ saydana + karuna +mudita) unless you realize that one's whole attitude to life must change- and for the better. To attain and sustain genuine loving kindness is a discipline that requires cleansing from the inside out and from the outside in, especially in ridding oneself of emotional contaminants, avoiding destructive 


\section{Journal of Yoga and Physiotherapy}

self-centredness and engaging in preventative measures to enhance one's total harmony and health [11].

The Buddhist notion of loving kindness, then, has wide application in humanistic medicine, especially at the spiritual level, but one does not have to be a Buddhist or a health care professional to practice it. Everyone should practice it toward his or her family, friends, and associates [12]. Qi may be understood as vital energy. This energy (Qi) needs always to be balanced and in harmony so the body, mind, and spirit will be well aligned. In order to attain an optimum balance of harmony and alignment one needs to practice techniques of self-cultivation. Yoga, Qi Gong, meditation, or Tai Chi are some of the practices used to arrive at this level of self-cultivation.

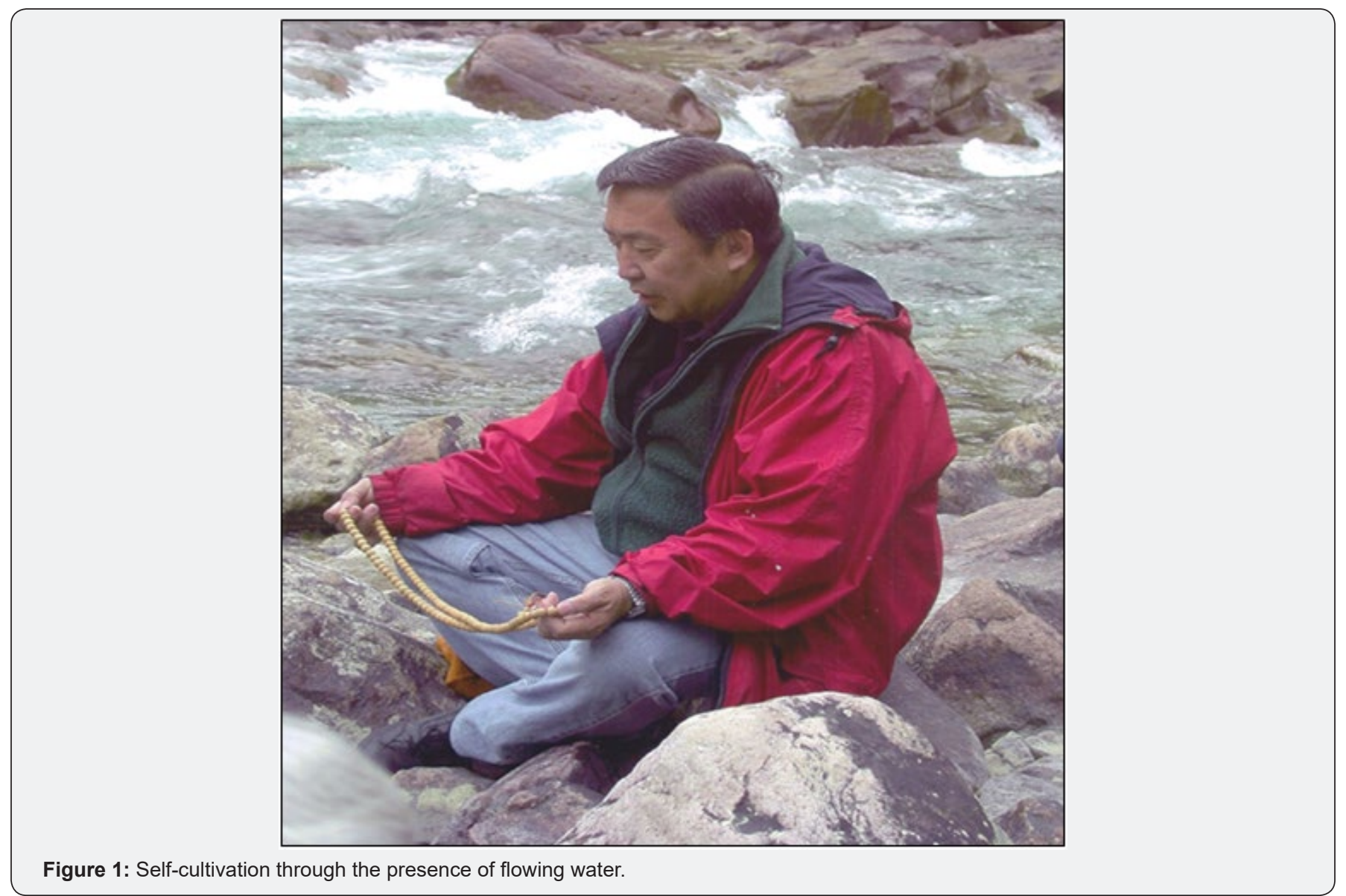

Even though we may practice the above techniques, we also need Mother Nature to enhance our energy. Therefore, the sea, trees, mountains, and wildlife add extraordinary depth to our experience in the retreat. The Qi can be cultivated either individually or in a group. When Qi Gong is practiced on an individual basis it is easier to be more self-paced. However, when practiced in a group you may be greatly helped by the more inter-dependent and inter-connected nature of the experience. There are many ideal locations to hold retreats such as: Fortress Mountain (in the Canadian Rockies), Hollyhock (Cortez Island, British Columbia), Dharma Centre of Canada (Kinmount, Ontario), and others. The location ought to include excellent Feng Shui with positive and healing energy. Feng Shui and energy will enhance the retreat and experience of the participants. The retreat will offer profound insights and understanding of healing energy and how to cultivate, purify, and recycle it (Figure 1).

Qi Gong encompasses breathing, concentration, posture, movement, and stretching exercises. The objective is to attain balance in physical, mental, spiritual, and energy alignment or harmonization. Classic and newly created exercises are taught during the retreat. Participants are given individual attention and assignments according to their specific needs. All of the retreat exercises are designed to take advantage of the natural light and wilderness. These sessions include participants being near trees, coves, water (oceans/seas/rivers/lakes/creeks), small/big rocks, and/or sand. For many individuals hugging a tree is the highlight of the retreat. Tree hugging is the exchange of energy between a human and nature while simultaneously aligning the person's vital energy. Early morning walking Qi Gong exercises keep the body, mind, and spirit balanced and harmonized, while ventilating and grounding human energy. Retreats are rarely cancelled due to adverse weather conditions. Adverse weather conditions may challenge our determination and discipline yet help us appreciate and understand more about Mother Nature's moods.

Retreat participants may also experience phonation or chanting exercises to open energy centres (chakras) and harmonize their organs. Within the context of the traditional Chinese medical system, sound or music therapy affects the body, 
mind, and spirit in three ways. The first is through listening, which involves the reception of sounds through the ear to eight cranial auditory nerves. This stimulates the major internal organs, especially the kidney, which pertains to the ear and hearing. Secondly, when producing sounds and singing, we are stimulating two other major internal organs, namely, the lungs and stomach. This pertains to the zhong qi (pectoral vital energy) of the stomach. Thirdly, music therapy often involves listening, singing and dancing at the same time. This helps to not only stimulate the kidney, lung, and stomach but also to unblock the qi flow of the 14 regular and also the 8 extraordinary meridians, enhancing the superficial, intermediate, and deep levels of qi circulation and opening up the chakras. Therefore, the effect is holistic and powerful for one's whole being, no matter what age, gender, culture, or era [13].

In the Buddhist healing perspective, a mantra, which involves repeating a sequence of tones over and over again is a powerful technique for opening up the chakras, balancing the meridians, harmonizing the internal organs, engaging in meditation and cultivating loving kindness for all sentient beings. The emphasis is on simplicity. The experience of repetition has a calming effect on your mind because it fills your mind and holds your focus throughout the process [14].

"Chakra" means wheel in ancient Sanskrit, and they are considered major vital energy (Qi) centres of the human body, mind, and spirit. They are thought to spin in a clockwise direction for males and a counter clockwise direction for females, at different rates, manifesting the spinning shape of a funnel spiraling inward- like a tornado. They correspond to various major energetic acupuncture points in the traditional Chinese medical system [15].

The retreat training develops the participant's six senses such as vision, hearing, smell, taste, feeling (physical/emotional), and intuition. Mother Nature enriches our senses and the entire retreat experience. Qi (energy) is cultivated and then purified. Later negative energy is recycled into positive healing energy and a higher stage of awareness develops. This tranquil environment combines with inner peace of mind and spirit to help individuals become more self-aware and better at self-healing. Above all the healing has to start from the inside and then later transform to the outside world. This may ultimately contribute to world peace, international harmony, and universal healing.

Retreats enhance the quality of life within a social and natural environment. Participants are inspired to be mutually supportive and caring for one another like compassionate family members. Retreat members are encouraged to experience, appreciate, and contribute to the spirituality of the natural environment. This is the positive, healing energy that is immanent at many retreats. In traditional Chinese medicine it is viewed as good Feng Shui (environmental medicine). Enhancing the quality of life has a universal dimension. The Buddhist, Taoist, and medical style of Qi Gong that I teach emphasizes the necessity of cleansing oneself of emotional contamination. This refers to the anger, fear, depression, or sadness caused by difficult circumstances or stress. It is essential to transform or recycle this negative energy into positive energy. By offering genuine blessings and loving kindness to all sentient beings the retreat becomes an opportunity to heal for all. This is a fundamental principle of physical, mental, and spiritual empowerment as well as self-care. Therefore, we conduct candlelight and sandalwood blessings. At the same time I offer life advice and a spiritual gift at the end of the retreat.

Retreats teach participants how to use the best out of Mother Nature to balance, harmonize, and align themselves. Participants learn how to purify their physical, mental, and spiritual energy. At the same time they better understand how to transform their negative (suffering) energy to positive (healing) energy. Everybody needs to heal themselves, others, and make the universe a more healing and peaceful place for future generations. This is a human responsibility. It must be noted that many other therapies, such as Tai Chi Chuan, Yoga, various relaxation techniques, and spiritual healing, are as amenable as Qi Gong to the retreat experience. Moreover, retreats are for everyone, especially health care practitioners, who must take good care of themselves so that they can take better care of their dear patients. After all, nothing is more important in life than taking good care of others and ourselves [16].

\section{Conclusion}

In my life I have found that Qi Gong is the best thing for me. No matter which profession you follow or what walk of life you are in having good Qi is essential. The interesting thing is, I've found that a lot of people think Qi Gong is just an exercise, but it is really an exercise of body, mind, and spirit. Qi Gong is also a health discipline through which you can help not only yourself, but also give a person who is not well the capacity to create his or her own well-being. So, Qi Gong is not self-cultivation alone, for a patient who has learned Qi Gong is probably readier for treatment. People who practice Qi Gong make it easier for a practitioner to treat them because they are already well aligned. Then all you need to do is just give them a tiny bit of healing and it goes right in! [17]

That's why I have found Qi Gong a very important thing for the community. Everybody should practice Qi Gong every morning. If everybody would learn to practice Qi Gong, like they brush their teeth and wash their face, they'd become responsible for their own health. And then only when you need help, you go to a practitioner, and he or she readjusts any imbalances for you and you become healthy again [18].

Healing can only take place between people who respect and love each other. When there is no feeling, there is no medicine. When there is no medicine, then there is no healing. The interesting thing about medicine is not only the treatment, but also the intention of treatment. The person who treats should not just be a therapist, but also a healer. And in order to become a healer, one has to cultivate himself or herself to be, what we call in spiritual terms, purified, and while treating with good intentions and loving-kindness [19]. 


\section{Journal of Yoga and Physiotherapy}

\section{References}

1. Aung SKH (1996) Loving Kindness- The Essential Buddhist Contribution to Primary Care. Hum Health Care Int 12(2): E12.

2. Aung SKH (2000) Traditional Secrets of Wellness: Dr. Aung Hands Down Ancient Chinese Pearls of Wisdom for Modern Living, College of Integrated Medicine, (1 $1^{\text {st }}$ edn), Edmonton, Canada, p. 1.

3. Aung SKH (2000) Traditional Secrets of Wellness: Dr. Aung Hands Down Ancient Chinese Pearls of Wisdom for Modern Living, College of Integrated Medicine, ( $1^{\text {st }}$ edn), Edmonton, Canada, p. 1.

4. Aung SKH (2000) Traditional Secrets of Wellness: Dr. Aung Hands Down Ancient Chinese Pearls of Wisdom for Modern Living, College of Integrated Medicine, ( $1^{\text {st }}$ edn $)$, Edmonton, Canada, pp. 9-10.

5. Aung SKH (2000) Traditional Secrets of Wellness: Dr. Aung Hands Down Ancient Chinese Pearls of Wisdom for Modern Living, College of Integrated Medicine, ( $1^{\text {st }}$ edn), Edmonton, Canada, pp. 9-10.

6. Aung SKH (2000) Traditional Secrets of Wellness: Dr. Aung Hands Down Ancient Chinese Pearls of Wisdom for Modern Living, College of Integrated Medicine, ( $1^{\text {st }}$ edn $)$, Edmonton, Canada, pp. 9-10.

7. Aung SKH (2000) Traditional Secrets of Wellness: Dr. Aung Hands Down Ancient Chinese Pearls of Wisdom for Modern Living, College of Integrated Medicine, ( $1^{\text {st }}$ edn $)$, Edmonton, Canada, pp. 9-10.

8. Aung SKH (2000) Traditional Secrets of Wellness: Dr. Aung Hands Down Ancient Chinese Pearls of Wisdom for Modern Living, College of Integrated Medicine, ( $1^{\text {st }}$ edn), Edmonton, Canada, pp. 9-10.

9. Aung SKH (2000) Traditional Secrets of Wellness: Dr. Aung Hands Down Ancient Chinese Pearls of Wisdom for Modern Living, College of Integrated Medicine, ( $1^{\text {st }}$ edn), Edmonton, Canada, pp. 9-10.

10. Aung SKH (2000) Traditional Secrets of Wellness: Dr. Aung Hands Down Ancient Chinese Pearls of Wisdom for Modern Living, College of Integrated Medicine, ( $\left(1^{\text {st }}\right.$ edn $)$, Edmonton, Canada, pp. 9-10.
11. Aung SKH (2000) Traditional Secrets of Wellness: Dr. Aung Hands Down Ancient Chinese Pearls of Wisdom for Modern Living, College of Integrated Medicine, ( $1^{\text {st }}$ edn), Edmonton, Canada, p. 10

12. Aung SKH (2000) Traditional Secrets of Wellness: Dr. Aung Hands Down Ancient Chinese Pearls of Wisdom for Modern Living, College of Integrated Medicine, ( $\left(1^{\text {st }}\right.$ edn $)$, Edmonton, Canada, p. 10

13. Aung SKH (2002) "Qigong Sounds: Medical Therapy Through Phonation." Qi: The Journal of Traditional Eastern Health \& Fitness 11(4): 40.

14.Aung SKH (2002) "Qigong Sounds: Medical Therapy Through Phonation." Qi: The Journal of Traditional Eastern Health \& Fitness 11(4): 40.

15. Aung SKH (2002) "Qigong Sounds: Medical Therapy Through Phonation." Qi: The Journal of Traditional Eastern Health \& Fitness 11(4): 40.

16. Aung SKH (2000) Traditional Secrets of Wellness: Dr. Aung Hands Down Ancient Chinese Pearls of Wisdom for Modern Living. College of Integrated Medicine, ( $1^{\text {st }}$ edn), Edmonton, Canada, p. 22

17. Aung SKH (2007) "Compassionate Care-An Emerging Medical Paradigm: An Interview with Dr. Steven KH Aung." Harmony: Ancient Wisdom for Modern Wellness (the newsletter of the Traditional Chinese Medicine World Foundation.): 7.

18. Aung SKH (2007) "Compassionate Care-An Emerging Medical Paradigm: An Interview with Dr. Steven KH Aung." Harmony: Ancient Wisdom for Modern Wellness (the newsletter of the Traditional Chinese Medicine World Foundation.): 7.

19.Aung SKH (2007) "Compassionate Care-An Emerging Medical Paradigm: An Interview with Dr. Steven KH Aung." Harmony: Ancient Wisdom for Modern Wellness (the newsletter of the Traditional Chinese Medicine World Foundation.): 1.

Your next submission with Juniper Publishers
will reach you the below assets
- Quality Editorial service
- Swift Peer Review
- Reprints availability
- E-prints Service
- Manuscript Podcast for convenient understanding
- Global attainment for your research
- Manuscript accessibility in different formats
( Pdf, E-pub, Full Text, Audio)
- Unceasing customer service
Track the below URL for one-step submission
https://juniperpublishers.com/online-submission.php

